DOI 10.5216/ia.v46i3.63825

\title{
A AÇÃO DOCENTE COM ESTUDANTES COM DEFICIÊNCIA INTELECTUAL NA ESCOLA ESPECIAL
}

\author{
itale Luciane Cericato \\ Universidade Federal de São Paulo (UNIFESP), Diadema, São Paulo, Brasil \\ ANDERSON RICARDO JÚNIOR DA ROCHA SILVA \\ Universidade Federal de São Paulo (UNIFESP), Diadema, São Paulo, Brasil
}

\begin{abstract}
Resumo: Este trabalho investiga a ação de uma professora da escola especial na organização de situações favorecedoras ao ensino e aprendizagem de estudantes com deficiência intelectual. Os dados, analisados com base na psicologia de Vigotski e coletados por entrevistas e observação das aulas, evidenciaram que a professora organiza sua prática focando o treino de habilidades de vida prática e diária, em acordo com as diretrizes da escola e com suas concepções sobre as potencialidades dos estudantes; atribui à formação especializada a mesma relevância dos saberes da prática profissional, e tem sua ação apoiada por equipe institucional multidisciplinar. No que se refere a esse último aspecto, sugere-se discutir possibilidades para que iniciativas semelhantes sejam replicadas como apoio à proposta da educação inclusiva e ao desafio de construir uma escola de qualidade para todos.
\end{abstract}

Palavras-chave: Deficiência Intelectual. Formação de Professores. Prática Pedagógica.

INTRODUÇÃO

A pesquisa objetiva compreender a ação de uma professora da escola especial na organização de situações favorecedoras do processo ensino e aprendizagem de estudantes com deficiência intelectual. Para tal, busca-se responder, especificamente, as seguintes perguntas: quais recursos são utilizados para mediar as situações de ensino e aprendizagem do estudante com deficiência intelectual? Qual é a natureza desses recursos e como são utilizados? A concepção da professora sobre deficiência intelectual influencia na organização das situações de ensino e aprendizagem? Como os saberes necessários para ensinar estudantes com deficiência intelectual foram construídos?

Espera-se que a pesquisa contribua com o campo da formação de professores, evidenciando elementos que constituem a prática docente com estudantes com deficiência intelectual. Com relação à compreensão e à problematização dessa prática, almeja-se ser possível levantar reflexões que subsidiem a formação profissional docente em nível inicial ou continuado, aspecto relevante no cenário de escassez de professores especializados no trato com as diversas deficiências, e especificamente com a deficiência intelectual, nas diferentes redes de ensino do país, como atestam as pesquisas de Nozi e Vitaliano (2012) e Glat e Nogueira (2003).

Estudar uma instituição especializada, e não uma escola comum em um contexto em que as políticas educacionais indicam a importância da educação inclusiva como direito de todos os estudantes, não foi uma escolha aleatória. Diversos 
pesquisadores evidenciaram, como já mencionado, a problemática das lacunas presentes na formação e na prática dos professores que atuam com pessoas com deficiência na escola comum (Nozi e Vitaliano, 2012); (Ferreira, 2006); (Glat et al, 2006); (Pletsch, 2009); (Rodrigues, 2008); (Vitaliano, 2007, 2010); (Bezerra e Araújo, 2011). Por essa razão, e buscando compreender o processo de ensino e aprendizagem direcionado a esse grupo, escolhemos estudar o assunto na perspectiva de um professor especializado, na expectativa de ser possível conhecer melhor as características que compõem sua atuação e formação. Isso não significa que nos contrapomos à proposta da educação inclusiva, mas desejamos explorar elementos formativos que possam fomentá-la com mais cuidado. Além disso, a literatura sobre a temática indica uma necessária articulação, amparada em noções de responsabilidade coletiva e trabalho colaborativo entre os professores das classes de educação especial e os das classes regulares, objetivando aperfeiçoar as situações que compõem o processo de ensinoaprendizagem dos estudantes (TAVARES; SANTOS; FREITAS, 2016).

\section{FUNDAMENTOS TEÓRICOS E PROCEDIMENTOS METODOLÓGICOS}

Para alcançar o objetivo proposto, foram selecionadas escolas de educação especial, situadas na região metropolitana do Estado de São Paulo, especializadas em atender pessoas com deficiencia intelectual. Dentre as instituições selecionadas, a que demonstrou interesse em participar da pesquisa tem promovido, em sua trajetória, o tratamento e a prevenção da deficiência, contribuindo com o bem-estar do sujeito ao articular assistência social e educacional com a defesa dos direitos das pessoas com deficiência, na perspectiva da inclusão social. Oferece atividades complementares de Arte e Educação Física. A equipe é formada por pedagoga, professores de Educação Artística e Educação Física, assistente social, psicóloga, fonoaudióloga, terapeuta ocupacional, coordenadora pedagógica e profissionais de limpeza, cozinha e segurança.

O primeiro contato foi realizado com a direção da escola que, após autorizar a entrada dos pesquisadores em campo e fornecer as informações sobre a caracterização da instituição, indicou alguns professores para integrarem o estudo. Do critério para seleção dos professores constava possuir, ao menos, cinco anos de atuação com estudantes com deficiência intelectual. Esse tempo é considerado, de acordo com os estudos de Huberman (2000), o período em que se inicia a estabilização do docente em sua profissão. Dentre os professores indicados, uma aceitou participar da pesquisa por meio da assinatura do Termo de Consentimento Livre e Esclarecido, conforme prevê a resolução no. 466/12 do Conselho Nacional de Saúde.

A professora participante tem 51 anos, é solteira, não tem filhos e atua na área docente há 20 anos. Sua formação superior foi realizada em instituições particulares. Cursou magistério e pedagogia. Estudou até o quarto ano de psicologia, mas não concluiu. Fez especializações nas áreas de autismo, deficiência intelectual e deficiência múltipla. A entrevista aconteceu durante o período de aulas enquanto os estudantes faziam atividades com outros professores.

Os dados foram coletados por meio de entrevista semiestruturada, realizada de modo recorrente, gravada para posterior transcrição, abordando o trabalho realizado e 
suas circunstâncias. Adicionalmente realizaram-se observações das aulas, pautadas por um roteiro estruturado com foco na relação professor-aluno, seleção de atividades, recursos didático-pedagógicos explorados, intencionalidade, tempo, entre outras informações. As observações foram feitas até atingir o critério de saturação. Os dados foram sistematizados para análise mediante a construção dos tópicos: formação docente; organização do trabalho pedagógico; concepções sobre a deficiência intelectual; e condições encontradas na realização do trabalho. Esses tópicos emergiram após exaustivas leituras do material originado nas entrevistas e buscaram, de acordo com o proposto por Duarte (2004), construir um sentido ao mosaico de informações coletadas, tendo como referência os pressupostos teóricos, filiação acadêmica e objetivos dos pesquisadores.

A compreensão teórica sobre deficiência intelectual que orientou o processo investigativo é a desenvolvida pela psicologia histórico-cultural proposta por Lev Vigotski (2018), que enfatiza a importância da interação do homem com o mundo social na construção dos processos psíquicos.

\title{
APRESENTAÇÃO, ANÁLISE E DISCUSSÃO DOS DADOS
}

Formação docente

Sobre como avalia a formação que recebeu para o exercício do trabalho pedagógico com os estudantes com deficiência intelectual, a professora explica:

\begin{abstract}
Eu acho que a teoria é a base de tudo para a gente lidar com eles, principalmente com os nossos alunos, mas eu acho que a prática também entra juntamente com a teoria (...) Eu fiz um curso para autismo... São experiências, são bagagens, são profissionais que vão lá, que falam do dia a dia, porque não existe uma receita, então o aluno vem, tem certos momentos que a teoria não vale de nada, mas a prática sim, mas tem alguns cursos que acrescentam, porque dá para a gente trabalhar com eles algumas coisas, aplicando algumas técnicas, entendeu? Então eu acho que para mim é muito importante, inclusive até a pós-graduação também é de fundamental importância (...) Estudar é muito bom, é um crescimento maravilhoso para o ser humano, e a gente vê outras coisas, vê outros pensamentos, tem outra forma de pensar e de agir com eles, então para mim foi de suma importância essa pós.
\end{abstract}

A professora atribui à sua formação papel basilar na prática da atividade docente. No entanto, enfatiza que a estruturação de seu ofício não se sustenta somente nos aspectos teóricos de sua formação profissional, e aponta outras dimensões que contribuem para o exercício da atividade pedagógica para promover o ensino e a aprendizagem dos estudantes. Demonstra compreensão de que a ação pedagógica não se fundamenta apenas em teorias e métodos de ensino obtidos em cursos de formação profissional, e, sim, que as atuações do professor em classe são capazes de produzir saberes que alicerçam o seu trabalho. Essa é uma visão encontrada na literatura, defendida por Tardif (2002), que afirma que os saberes docentes são múltiplos e construídos pela combinação de diversos fatores com os quais os professores 
relacionam-se de formas distintas. Esses saberes são resultado da formação profissional, mas também oriundos dos currículos e da prática cotidiana.

Para Tardif (2002), são quatro os tipos de saberes implicados na atividade docente: os saberes da formação profissional (ciências da educação e a ideologia pedagógica); os saberes disciplinares (diferentes campos do conhecimento); os saberes curriculares (programas escolares, objetivos, conteúdos e métodos que os professores devem aprender e aplicar); e, por fim, os saberes experienciais. Esses últimos são produzidos pela vivência de situações específicas relacionadas ao espaço da escola e às relações estabelecidas com alunos e colegas de profissão. "Incorporam-se à experiência individual e coletiva sob a forma de habitus e de habilidades, de saber-fazer e de saberser" (TARDIF, 2002, p. 38).

Para Duarte (2003), Tardif é um autor que coloca a questão epistemológica no centro do debate sobre formação de professores ao propor um protagonismo dos saberes da prática pedagógica que encontram eco na atividade docente. Para o autor, essa é uma postura problemática porque dela pode decorrer um preocupante recuo da teoria nos processos formativos, gerando práticas puramente reflexivas, descoladas de fundamentos teóricos e metodológicos que as alicercem; opinião com a qual concordamos. Moraes (2001) também vê com preocupação o movimento de desvalorização do saber teórico ao afirmar que

\begin{abstract}
A celebração do "fim da teoria" - movimento que prioriza a eficiência e a construção de um terreno consensual que toma por base a experiência imediata ou o conceito corrente de "prática reflexiva" - se faz acompanhar da promessa de uma utopia alimentada por um indigesto pragmatismo (...). Em tal utopia pragmatista, basta o "saber fazer" e a teoria é considerada perda de tempo ou especulação metafísica e, quando não, restrita a uma oratória persuasiva e fragmentária, presa à sua própria estrutura discursiva (MORAES, 2001, p. 10).
\end{abstract}

Para a autora, esse movimento é produto da ação de elementos como políticas educacionais preocupadas com a produção de resultados a serem alcançados em prazos exíguos; o empresariamento do ensino e o processo educacional inserido de forma cada vez mais intensa em uma dinâmica econômica/comercial. Apontamos, nesse sentido, a necessidade da construção de caminhos que, sem desmerecer a experiência docente, considerem os saberes produzidos academicamente nos processos formativos.

Organização do trabalho pedagógico

Sobre como planeja o trabalho com os estudantes, a professora diz que

Primeiro tem uma equipe, por isso eu tenho uma coordenadora, a gente trabalha com o planejamento anual e trabalhamos com projetos, no início do ano. Recebemos a sala e eu vou ver qual nível essa sala está, desde a idade; como eu estou com alunos de 15 a 30 anos, eu não vou dar uma coisa infantilizada, só que eu também 
CERICATO, I. L.; SILVA, A. R. J. da R.

não posso dar uma coisa referente à idade mental, porque a cronológica não vai me corresponder, então eu tenho todo um preparo para fazer o planejamento, o que vai ser trabalhado, qual a proposta da sala, isso eu recebo da minha coordenação, e, a partir da proposta da sala, eu vou montar o meu planejamento.

A proposta dessa sala é: vou ler, favorecer o desenvolvimento pessoal, a compreensão de competências sociais e das atitudes inerentes ao mundo do trabalho, desenvolver autonomia e maturidade, que permite a compreensão e o treino para inserção e manutenção no ambiente de trabalho, proposta diferenciada de trabalho, que visa à aquisição de competências e habilidades, bem como valores, atitudes sociais, oportunizando a educação para a cidadania. Então eu recebi o alunado e recebi essa proposta de trabalho, é a partir disso que eu vou montar o meu planejamento.

A professora informa que a organização de sua ação se dá em colaboração com a coordenação pedagógica para construir o planejamento das aulas e os objetivos educacionais propostos para os estudantes. A professora demonstra ainda que a elaboração das atividades a serem desenvolvidas com os estudantes é pautada pelo planejamento pedagógico cuja avaliação segue as perspectivas de aprendizagem AVD (atividades da vida diária) e AVP (atividades da vida prática). Essas duas perspectivas estão associadas ao desenvolvimento cognitivo e à promoção da independência dos alunos.

Sobre as metodologias que utiliza para o alcance dos objetivos propostos, a professora afirma que

\begin{abstract}
Método até existe, agora se ele vai alcançar o objetivo... No entanto, a nossa avaliação é totalmente... Não existe aquela avaliação, eu vou avaliar ele só com isso, ela é mutante, ela é constante, se não deu de um jeito eu vou tentar de outro, é quando eu falo para você na questão do nome, na verdade é mais treino, é puro treino que eu faço com eles, tem alguns que não conseguem. Então o que eu fiz? Eu peguei as letras móveis, fomos lá, recortamos os nomes deles, trabalhei com letras móveis. Se não der certo, eu vou trabalhar... Tem aluno que eu faço ainda questão da coordenação motora fina, de pontilhagem, porque ele ainda não está preparado para algumas coisas, então, aqui na sala, eu tenho 13 alunos, mas nenhum é igual, tem o que escreve a cursiva, tem o que escreve a bastão e tem o que não escreve nada. Então a minha metodologia é variada, porque, para cada um, eu tenho que usar um método para atingir o objetivo.
\end{abstract}

A professora parece compreender que cada estudante possui uma necessidade individualizada e, com base nisso, seleciona as estratégias de ensino que considera mais adequadas para atender às particularidades de cada um deles. Vigotski (2018, p. 5) afirma que "a criança mentalmente atrasada não é feita apenas de lacunas e defeitos, seu organismo como um todo se reconstrói. Toda a personalidade equilibra-se, é compensada por processos de desenvolvimento infantil". Nesse sentido, o autor aponta para uma concepção de educação que, em vez de valorizar o déficit, valoriza o que há para ser desenvolvido na pessoa, por meio de arranjos engendrados no seio das relações 
com o social, com a cultura. Tal aspecto se evidencia na prática da professora por meio da seguinte verbalização:

Recursos eu acho que tem muitos: jogos, brincadeiras, eu acho que tudo que a gente faz aqui na escola é válido. Eu digo assim, não quer dizer que só porque a gente está lá fora, em uma atividade de socialização, que ele não esteja aprendendo. Ou, de repente, a gente aplicar uma brincadeira, não existe um recurso assim, ah não, eu vou usar esse, e esse vai ter que dar certo. Não! São vários, a gente tem vários recursos. Recurso é tudo! É o brincar lá fora, é aqui dentro, dentro da sala de vídeo, ou na sala de artes, ou na aula de Educação Física.

Sobre o modo como organiza o processo avaliativo, a professora menciona que

A avaliação é através de um processo. Não é através de prova, não é através de teste, não é através de nada disso. A avaliação se dá no dia a dia, nas atitudes deles. E no final a gente tem alguns recursos que a gente vê se o aluno atingiu ou não, que aí, antes do final do ano, a gente tem um registro, que a gente faz sobre a sala e mais para o final do ano, que aí é individual, são quatro registros que a gente faz, são relatórios bimestrais, então, em cada bimestre a gente faz os relatórios das salas, e no final do ano é individual de cada aluno. A gente não avalia por nota. A gente vai avaliando, ele atingiu o objetivo ou ele não atingiu, ele socializou ou não, permaneceu durante o ano o mesmo, do início, meio e fim? A minha avaliação é assim.

A professora demonstra que realiza as avaliações traçando um perfil das habilidades desenvolvidas pelos estudantes e apontando aquelas que ainda necessitam ser conquistadas. De modo geral, são observadas questões que envolvem a comunicação, a socialização, a motricidade e a cognição, requisitadas na realização das atividades de vida prática e vida diária que constam como objetivos estabelecidos no planejamento pedagógico. Tais aspectos são coerentes com o que apontam Honora e Frizanco (2008), as quais afirmam que indivíduos com limitações intelectuais, de acordo com a intensidade com que a deficiência se manifesta, podem apresentar desproporções no desenvolvimento da motricidade, da cognição, da comunicação e na dimensão socioeducacional. Assim, instrumentos de avaliação que sejam capazes de mediar e acompanhar o desenvolvimento dessas habilidades são fundamentais para o processo de ensino e aprendizagem desses estudantes.

Sobre o processo de avaliação, perante os objetivos educacionais propostos pela instituição em conjunto com a professora, identificamos a preocupação de se construir uma avaliação formativa, contínua, compreendendo o ritmo de desenvolvimento e aprendizagem de cada estudante. Assim, ao mesmo tempo que estabelece objetivos a serem alcançados, o processo avaliativo não desconsidera as implicações que os aspectos de desenvolvimento dos estudantes com deficiência 
CERICATO, I. L.; SILVA, A. R. J. da R.

intelectual podem causar ao processo educacional. Concepções sobre a deficiência intelectual

Sobre a concepção pessoal acerca da deficiência intelectual, a professora compreende que

É um processo muito lento, não quer dizer que eles não vão alfabetizar, pode ser que sim, como pode ser que não. Tem alunos aqui que podem ser até alfabetizados. Eu tenho alunos, eu vou falar no geral, não só daqui, mas eu tenho alunos que são alfabetizados, que sabem ler, que usam o computador normalmente e que fazem a leitura, só que têm um déficit de atenção, um déficit de inteligência, que não dá pra acompanhar. Por exemplo: ele não vai estar em um colégio, ele não vai estar em uma faculdade, isso ele não tem condições de deslanchar, mas ele pode pegar um ônibus sozinho. Ele não vai viver sozinho, mas dá pra ele viver normalmente como qualquer ser humano. Agora, o ensino e aprendizagem na questão de alfabetização não é o foco aqui. $A$ gente não está aqui para alfabetizar eles. Alfabetizar seria no ensino regular mesmo, mas, assim, no caso eu vou falar do meu trabalho; na preparação para o trabalho eu tento fazer com que eles consigam, pelo menos, escrever o nome deles, isso para mim já basta. Eu não quero que ele escreva, que ele leia, que ele faça uma carta, que ele redija algum texto, mas, sim, que pelo menos o nome dele ele consiga fazer.

A professora parece explicitar que a deficiência intelectual impõe limitações ao processo de ensino e aprendizagem que, por consequência, repercute nas práticas educacionais. Segundo Nuernberg (2008), essa percepção da deficiência intelectual se estrutura de maneira problemática por partir da limitação dos alunos, e não de suas potencialidades. A percepção da condição psíquica como estrutura inerte, associada a um processo de ensino que se debruça sobre as limitações intelectuais, em vez de potencializar, reduz as oportunidades de desenvolvimento do sujeito de modo a condenar o processo educacional aos limites intelectuais particulares à deficiência. $\mathrm{O}$ processo educacional centrado nas limitações orgânicas não viabiliza as possibilidades de aprendizagem da pessoa com deficiência intelectual, porque não considera os elementos socioculturais como o instrumental necessário para a dilatação e o refinamento das habilidades e competências humanas.

De acordo com Vigotski (2018), o processo educacional, apoiado nos elementos socioculturais e nas potencialidades do estudante, e não em seus déficits - embora estes não sejam ignorados -, busca fazer com que a deficiência não seja o elemento mais importante, mas, sim, a resposta dada pelo estudante na dimensão da sua personalidade e de sua configuração orgânica diante das limitações encontradas no percurso de seu desenvolvimento.

A concepção sobre deficiência que se desdobra na relação ensino e aprendizagem é corroborada pela visão que a professora expressa sobre o currículo a ser ensinado aos estudantes. Quando indagada sobre o que pensa a respeito do que ensina, a professora responde: 
Eu acho que é o correto, até porque é um currículo funcional. Para a gente fica até mais fácil do que ensinar, de repente, uma matéria, aqui são coisas do dia a dia deles, eu não vou ensinar nada que eles não façam, são questões básicas de sobrevivência, se comportar, higiene, uma socialização, uma brincadeira. Permitir e passar para eles que eles podem fazer isso e muito mais. Tem alunos que chegam e, por conta da deficiência, eles não fazem nada em casa, é tudo o que a família faz, os meus não, o ALUNO Z vive na rua, ele traz vivência de rua, por quê? Porque ele vive na rua, acho que mãe e pai trabalham, eu não sei se você já percebeu, ele vem com a chave pendurada, então ele tem uma dependência. Falando de outros alunos, tem alunos que não têm condições de ir ao banheiro e a família tem que ajudar, e essas condições os meus alunos têm, tem alguns que ainda não, mas ele está caminhando para, e a gente está fazendo um trabalho para caminhar, para que ele possa ter uma condição de tomar banho sozinho, de ir ao banheiro, se limpar sozinho, de ter autonomia, de ele ir na cozinha abrir a geladeira da casa e pegar alguma coisa que ele queira comer, e não que a mãe vai oferecer. Então eu acho que esse currículo, para mim, é gostoso trabalhar porque é o dia a dia deles, atividade da vida diária e prática deles que a gente está desenvolvendo aqui de uma forma mais amena, de uma forma diferente. Quando a gente vai para a cozinha para preparar um bolo, essa semana nós fizemos uma torta, eu não sei se na casa deles eles têm essa vivência, até alguns eu percebo que têm porque pela afinidade que têm em lidar com a situação em que estão inseridos, mas tem uns que não lavam, não secam, não guardam, não mexem em uma panela, não vão para o fogão ou não abrem uma geladeira, isso aí tem, e a gente tem que passar isso para eles e tem que passar de uma forma que eles vão fazer, que eles são produtivos, que eles são capazes.

Aqui são evidenciados os objetivos do trabalho educativo proposto. Diferentemente da escola regular, cuja preocupação, embora não seja a única, é atender aos conteúdos relativos ao currículo escolar, na escola especial - que é um complemento -, é esperado que o professor seja detentor de metodologias específicas e bem delineadas para o atendimento individualizado ao estudante com deficiência, promovendo-lhe a emergência de funções psicológicas envolvidas com a autorregulação da conduta que envolve, entre outras coisas, o cuidado consigo mesmo, noções sobre vida autônoma, informações básicas sobre higiene, cuidados com o próprio corpo, questões referentes a situações específicas como frequentar estabelecimentos comerciais ou espaços sociais, ter estratégias para se defender de abusos e exploração na rua, em casa e em outras situações cotidianas. Tais habilidades costumam ser reconhecidas e incentivadas por meio da realização de oficinas de artesanato, dança, culinária, entre outras, de forma que tais exigências, por atenderem às necessidades do estudante, não lhes signifiquem esforços ou sofrimentos desnecessários (BEZERRA; ARAÚJO, 2011). 
Se, por um lado, o trabalho com as atividades de vida prática e vida diária é a preocupação maior do professor da escola especial - preocupação importante e legítima porque dá respostas às necessidades diárias dos estudantes -, por outro, vemos com apreensão o fato de a professora considerar que há limitações para o processo de desenvolvimento e aprendizagem de outras habilidades. Os processos mais relevantes no desenvolvimento humano são aqueles que ocorrem mediados pelas relações que se estabelecem com outras pessoas, ou seja, relações práticas e verbais entre os homens e o ambiente em que vivem. "Quando o objetivo desta atividade é transmitir à criança determinadas noções, capacidades e hábitos, dizemos que a criança aprende e o adulto ensina" (LEONTIEV, 2005, p. 96). Assim, é com base nesse pressuposto teórico que consideramos questionável o comentário da professora sobre as limitações cognitivas de alguns estudantes, porque o desenvolvimento humano, tal qual o compreendemos, decorre das experiências histórico-sociais, dos conhecimentos produzidos historicamente e que são apropriados pela pessoa fundamentalmente pelo processo de educação. Referimos-nos, em particular, a um processo educativo intencionalmente planejado, em que o professor se adianta ao modo de pensar do estudante, criando situações de ensino em grau de complexidade gradativo, capazes de impulsionar o desenvolvimento. Os estudos de Vigotski (2018) evidenciam que, se por um lado a deficiência implica dificuldades para o desenvolvimento da pessoa, há que se considerar, por outro, os fenômenos da compensação e da plasticidade do funcionamento humano, quando associados à qualidade das experiências vividas no grupo social. Assim, os limites não podem ser dados a priori pela existência da deficiência, mas pela carência ou inadequação das relações da pessoa com professores, colegas de turma e família que impedem "sua inserção na vida coletiva em que encontra as bases para construir suas funções internas, para fazer-se indivíduo" (CAVALCANTI, 2005, p. 12). Assim, é interessante perceber que a postura da professora parece remeter a uma contradição.

A ênfase que Vigotski (2018) atribui ao desenvolvimento baseado na qualidade das relações sociais a que a pessoa está sujeita decorre do fato de que, para ele, essas relações favorecem a emergência das funções cognitivas superiores (memória, atenção voluntária, percepção, imaginação, capacidade de planejamento, concentração, linguagem), que são mais educáveis que as funções cognitivas elementares (de caráter biológico), em especial porque, por vezes, na deficiência, estas últimas se encontram comprometidas organicamente.

A professora percebe que os estudantes correspondem aos desafios que ela Ihes apresenta, no que se refere ao aprendizado das atividades de vida diária e prática. No entanto, Ihe seria oportuno perceber que eles também poderiam corresponder, cada um a seu modo e tempo, a desafios de outra natureza, relacionados com outros aprendizados. Essa forma de a professora conceber o potencial de aprendizado dos estudantes persiste a despeito de toda a formação especializada que ela possui, indicando que, possivelmente, os processos formativos docentes devem incorporar, além de conhecimentos teóricos e metodológicos, também aqueles envolvidos com representações de base social acerca da deficiência.

Condições encontradas na realização do trabalho 
Ao se referir aos recursos que utiliza para alcançar seus objetivos com os estudantes, a professora esclarece que

\begin{abstract}
Um pouco da parte teórica é a vivência do dia a dia, alguma coisa a coordenação nos auxilia, como também a equipe técnica nos auxilia, tem momentos que a gente não tem como fazer a intervenção de um aluno que está em surto. Então tem que ter outro profissional para me dar um respaldo. Na verdade não sou eu que trabalho só, nós somos uma equipe multiprofissional, que tem a coordenadora pedagógica que vê, acompanha e orienta o meu trabalho, o que eu posso ou não posso fazer, de repente eu posso colocar coisas que ela fala: não, isso não vai dar para trabalhar com o grupo por tal motivo. Então, quer dizer, a minha estratégia que eu planejei também não deu, eu sou supervisionada para fazer aquilo que eu estou fazendo com eles.
\end{abstract}

Ao explicitar que se sente amparada para a realização do seu trabalho com os estudantes pela existência de uma equipe multidisciplinar, a professora também esclarece como é a dinâmica do trabalho dessa equipe:

Recebo (apoio) da coordenação, da psicóloga, enfim, da TO, fono. A gente tem o respaldo dessas técnicas. Dependendo do aluno, ele faz até terapia. Tem um momento que a psicóloga senta com ele lá, um dia da semana, todas as sextas-feiras, faz atendimento com determinado aluno. Não sou eu sozinha, com certeza.

A equipe multidisciplinar representa um suporte que apoia o trabalho realizado pela professora em sala de aula. Mais adiante, ela informa que esse suporte se efetiva, inclusive, com a discussão dos casos dos estudantes na busca pelo encontro coletivo das melhores estratégias de trabalho:

\begin{abstract}
Conversamos muito, inclusive aqui, como eles têm aula complementar de Artes e Educação Física, tipo assim, na minha sala ele pode ter um rendimento, mas na sala de Artes ele tem outro, na de Educação Física ele tem outro, alguns comportamentos que acontecem lá e não aparecem dentro da sala de aula, então a gente sempre está trocando. No entanto, quando é feito o conselho, o professor da sala, juntamente com as técnicas, a assistente social, a psicóloga, ou fono ou TO, a que estiver no caso juntamente com o professor de Artes e Educação Física, é uma equipe que quando a gente vai fazer o conselho, chega no final do ano a gente faz um conselho, e estão todos esses, porque cada um também vai falar: olha, na minha sala, por exemplo, ele teve tal comportamento, na sala de Artes ele teve o mesmo comportamento, ou sim, ou não, na de Educação Física, ele não fazia nenhuma atividade, estou dando um exemplo, entendeu? Mas são os três juntos.
\end{abstract}


O trabalho colaborativo aparece como um recurso importante que contribui para a professora ter mais segurança na realização de suas ações pela possibilidade de discussão e troca de experiências com seus pares. Fullan (2009, p. 133) afirma que "pressupõe-se que a melhora do ensino seja uma busca coletiva, em vez de individual, e que a análise, avaliação e experimentação com os colegas sejam condições em que os professores melhoram".

Cericato e Davis (2013) também destacam a cooperação profissional e o trabalho colaborativo como recursos importantes para o trabalho docente. Para as autoras,

A cultura da cooperação profissional está centrada na promoção de ações inovadoras, cujo foco está no desempenho bem-sucedido dos alunos, gerando, assim, sucesso para os professores. $\mathrm{O}$ trabalho coletivo permite aos professores a socialização de experiências bem (ou mal) sucedidas, a troca de informações, o debate, o diálogo, a possibilidade de observar seus pares e de ser por eles observados, a construção de critérios que definam uma prática pedagógica adequada, enfim, a elaboração conjunta de um projeto pedagógico vivo, focado tanto no processo de ensino como em seus resultados. (CERICATO E DAVIS, 2013, p. 286-287).

Assim, a existência dessa equipe multidisciplinar e seu funcionamento na instituição é um ponto positivo e um diferencial que, infelizmente, inexistem nas escolas regulares, tão carentes, como se sabe, de metodologias planejadas para o atendimento de estudantes com deficiência.

Se o apoio encontrado no trabalho realizado de modo colaborativo parece ser um ponto facilitador para a organização da prática pedagógica da professora, um ponto mencionado como dificuldade diz respeito a questões emocionais apresentadas pelos estudantes, como se pode observar no relato abaixo:

Não tem um caderno de receita, tem dias que a gente tem dificuldade sim, com uma situação, principalmente questões emocionais. Tem aluno que vem para a escola porque brigou com a família, ou teve um problema em casa, então, eu acho que essas questões é o que mais pega, mas não que eu tenha problema... $\mathrm{A}$ gente tenta lidar e tenta resolver, mas se vai conseguir ou não, aí é outra história.

Novamente a professora, embora tenha mencionado contar com estrutura de suporte e apoio para trabalhar com os estudantes, deixa transparecer que acredita nem sempre ser possível obter sucesso em sua ação. Isso parece se relacionar mais com suas concepções sobre as potencialidades dos estudantes, que, em nosso entendimento, poderiam ser revistas - inclusive em processos de formação profissional continuada -, do que com as condições mencionadas para a realização do trabalho. 


\section{CONSIDERAÇÕES FINAIS}

Nesta pesquisa, o estudo de ações e práticas da educação especial buscou fomentar reflexões sobre possibilidades formativas para professores da escola regular, considerando-se que ambas as modalidades de ensino possam atuar em regime de responsabilidade coletiva e trabalho colaborativo. Dessa forma, sem desconsiderar a importância das condições de infraestrutura das escolas, entende-se que a qualidade da formação docente é aspecto essencial para o sucesso da educação de qualquer criança e jovem, com ou sem deficiência, porque não há formação docente de qualidade descolada de saberes criteriosamente fundamentados. A prática dos professores precisa ser embasada em conhecimentos teóricos e metodológicos sólidos. Assim, sem desmerecer os saberes que os professores constroem em suas vivências profissionais, é preciso encontrar meios para que eles sejam incorporados com o rigor e a seriedade necessários aos processos formativos, combatendo-se o movimento da prática reflexiva pura, que apenas traz malefícios para as práticas educacionais.

Dentre os dados da pesquisa, convém destacar que, se por um lado a organização do trabalho pedagógico mostrou-se sistematizada, respeitosa ao ritmo de cada estudante, com estratégias personalizadas e com uma avaliação focada no percurso de aprendizagem, e não em seu resultado final, por outro, percebemos ainda a necessidade de desmistificar concepções que apregoam que o desenvolvimento da pessoa com deficiência intelectual é marcado pelo déficit, e não pelas potencialidades. Nesse aspecto, a professora parece desconsiderar que o desenvolvimento humano é favorecido pelas interações fomentadas na cultura e que a qualidade dessas interações permite o desenvolvimento de funções cognitivas mais sofisticadas ao homem. Subestimar o potencial de aprendizagem dos estudantes é um erro, conforme a concepção de desenvolvimento que norteia este estudo, segundo a qual "devemos direcionar toda atenção para revelar e superar a deficiência onde ela se mostra mais patológica" (VIGOTSKI, 2018, p. 19). Embora há anos os estudos de Vigotski tenham demonstrado, no campo educacional, a plasticidade do funcionamento humano quando associado à qualidade das experiências vividas no mundo social, ainda existe a necessidade de esses estudos serem reafirmados em processos de formação docente.

A existência de uma equipe multidisciplinar na instituição pesquisada, oferecendo suporte para o trabalho da professora, representa, sem dúvida, um diferencial importante como espaço de partilha de experiências e construção de estratégias focadas nos processos de aprendizagem. Porém, importa discutir meios para que iniciativas semelhantes possam ser integradas nas diferentes redes de ensino do país oferecendo apoio para a proposta da educação inclusiva. Se é desejável que a educação dos estudantes com deficiência ocorra, preferencialmente, nas escolas regulares, é preciso que os professores dessas instituições sejam formados e apoiados para a desafiadora tarefa de educá-los por meio do fomento de mediações, capazes de desenvolver neles as funções psíquicas superiores (Bezerra e Araújo, 2011). A junção de sólidas experiências formativas que permitam aos professores a condução de um processo pedagógico sistematizado e teoricamente fundamentado, aliado ao suporte encontrado em uma equipe multidisciplinar na qual se possa obter apoio, quando 
CERICATO, I. L.; SILVA, A. R. J. da R.

necessário, pode ser um caminho promissor. Para tanto, há de se investigar a viabilidade de políticas públicas que integrem as redes de saúde às redes de educação.

Esperamos que os dados apresentados contribuam com o campo da formação de professores, ao evidenciar os elementos que constituem a prática desses profissionais com estudantes com deficiência intelectual, e que esses dados possam subsidiar a reflexão sobre políticas educacionais relacionadas aos processos formativos em nível inicial ou continuado, com foco no desafio da construção de uma escola de qualidade para todos.

Artigo recebido em: 08/06/2020

Aprovado para publicação em: 30/11/2020

THE TEACHING ACTION WITH INTELLECTUALLY DISABLED STUDENTS IN SPECIAL SCHOOL

ABSTRACT: The research investigates the action of a teacher in a special school in the organization of favorable situations in the process of teaching and learning of students with intellectual disability. The data, analysed based on Vygotsky's psychology and collected by means of interviews in the classes, prove that the teachers organizes her practice focusing on the training of practical and daily skills in accordance with the guidelines of the school and her conceptions in regard to the potentialities of the students; she attributes to specialized formation the same relevance that she places on the knowledge of professional practice and that she has her actions supported by a multidisciplinary institutional team. It is suggested that possibilities for similar initiatives be replicated as support to inclusive education and to the challenge of building a quality school for all.

KEYWORDS: Intellectual Disability. Teacher Formation. Pedagogic Practice.

\section{LA ACCIÓN DOCENTE CON ALUMNOS CON DISCAPACIDAD INTELECTUAL EN LA ESCUELA ESPECIAL}

RESUMEN: La pesquisa busca investigar la acción de una docente de escuela especial en la organización de situaciones que favorecen el proceso de enseñanza y aprendizaje de los alumnos con discapacidad intelectual. Los datos, analizados según la psicología de Vygotsky y recopilados a través de entrevistas y observación de las clases, revelan que la docente organiza su práctica llevándose en cuenta el entrenamiento de habilidades prácticas y del cotidiano de acuerdo con las normas de la escuela y con sus concepciones sobre el potencial de los alumnos; atribuye a la formación especializada la misma importancia del conocimiento de la práctica profesional y tiene su acción respaldada por un equipo institucional multidisciplinario. Se sugiere analizar las posibilidades de repetir iniciativas similares en apoyo a la propuesta de educación inclusiva y al desafío de construir una escuela de calidad para todos.

PalABRAS ClAVE: Discapacidad Intelectual. Formación de Docentes. Práctica Pedagógica. 


\section{REFERÊNCIAS}

BEZERRA, G. F. B.; ARAÚJO, D. A. de C. De volta à teoria da curvatura da vara: a deficiência intelectual na escola inclusiva. Educação em Revista. Belo Horizonte. v. 27, n. 2, p. 277302, 2011. Disponível em: http://www.scielo.br/pdf/edur/v27n2/a13v27n2.pdf. Acesso em: 03 jun. 2020.

CAVALCANTI, L. S. Cotidiano, mediação pedagógica e formação de conceitos: uma contribuição de Vygotsky ao ensino de geografia. Caderno Cedes, Campinas, vol. 25, n. 66, p. 185-207, 2005. Disponível em:

https://www.scielo.br/pdf/ccedes/v25n66/a04v2566.pdf. Acesso em: 03 jun. 2020.

CERICATO, I. L.; DAVIS, C. L. F. Cooperação profissional: uma alternativa para a formação continuada de professores. In: MAIA, H, FUMES, N; AGUIAR, W. M. J. (Orgs.). Formação, atividade e subjetividade: aspectos indissociáveis da docência. $1^{\text {a }}$. ed. Nova Iguaçu: Marsupial Editora, 2013. E-book. Disponível em:

http://marsupialeditora.com.br/livros/formacao-atividade-e-subjetividade/. Acesso em: 03 jun. 2020.

DUARTE, R. Entrevistas em pesquisas qualitativas. Educar em revista. Curitiba, n. 24, p. 213-225, 2004. Disponível em: https://www.scielo.br/pdf/er/n24/n24a11.pdf. Acesso em: 03 jun. 2020.

DUARTE, N. Conhecimento tácito e conhecimento escolar na formação do professor (por que Donald Schön não entendeu Lúria). Educação \& Sociedade, Campinas, vol. 24, n. 83, p. 601-625, 2003. Disponível em: https://www.scielo.br/pdf/es/v24n83/a15v2483.pdf. Acesso em: 03 jun. 2020.

FERREIRA, W. B. Inclusão × exclusão no Brasil: reflexões sobre a formação docente dez anos após Salamanca. In: RODRIGUES, D. (Org.). Inclusão e educação: doze olhares sobre a educação inclusiva. São Paulo: Summus, 2006.

FULLAN, M. O significado da mudança educacional. Porto Alegre: Artmed, 2009.

GLAT, R.; NOGUEIRA, M. L. de L. Políticas educacionais e a formação de professores para a educação inclusiva no Brasil. Comunicações, ano 10, n. 1, p. 134-141, 2003. Disponível em: https://www.metodista.br/revistas/revistas-

unimep/index.php/comunicacoes/article/view/1647/1055. Acesso em: 03 jun. 2020.

GLAT, R. et. al. Formação de professores na educação inclusiva: diretrizes políticas e resultados de pesquisas. Anais do Encontro Nacional de Didática e Prática de Ensino, Recife, PE, Brasil, 13, 2006. 
CERICATO, I. L.; SILVA, A. R. J. da R.

HONORA, M.; FRIZANCO, M. L. Esclarecendo as deficiências: aspectos teóricos e práticos para contribuir para uma sociedade inclusiva. São Paulo: Ciranda Cultural, 2008.

HUBERMAN, M. O ciclo de vida profissional dos professores. In: NÓVOA, A. (Org). Vidas de professores. 2. ed. Porto: Porto, 2000.

LEONTIEV, A. N. Os princípios do desenvolvimento mental e o problema do atraso mental. In: LURIA, A. R.; LEONTIEV, A.; VIGOTSKI, L. S. Psicologia e pedagogia: bases psicológicas da aprendizagem. São Paulo: Centauro, 2005.

MORAES, M. C. M. Recuo da teoria: dilemas na pesquisa em educação. Revista Portuguesa de Educação, Braga, v. 14, n. 1, p. 7-25, 2001. Disponível em: https://www.redalyc.org/pdf/374/37414102.pdf. Acesso em: 03 jun. 2020.

NOZI, G. S.; VITALIANO, C. R. Saberes necessários aos professores para promover a inclusão de alunos com necessidades educacionais especiais. Revista Educação Especial, Santa Maria, v. 25, n. 43, p. 333-348, 2012. Disponível em: https://periodicos.ufsm.br/educacaoespecial/article/view/3343. Acesso em: 03 jun. 2020.

NUERNBERG, A. H. Contribuições de Vigotsky para a educação de pessoas com deficiência visual. Psicologia em Estudo, Maringá, v. 13, n. 2, p. 307-316, 2008. Disponível em: https://www.scielo.br/pdf/pe/v13n2/a13v13n2.pdf. Acesso em: 03 jun. 2020.

PLETSCH, M. D. A formação de professores para a educação inclusiva: legislação, diretrizes políticas e resultados de pesquisas. Educar em Revista, Curitiba, n. 33, p. 143156, 2009. Disponível em: https://www.scielo.br/pdf/er/n33/10.pdf. Acesso em: 03 jun. 2020.

RODRIGUES, D. Questões preliminares sobre o desenvolvimento de políticas de educação inclusiva. Inclusão - Revista Educação Especial, Brasília, v. 4, n. 1, p. 33-40, 2008. Disponível em: http://portal.mec.gov.br/seesp/arquivos/pdf/revinclusao5.pdf. Acesso em: 03 jun. 2020.

TARDIF, M. Saberes docentes e formação profissional. 12ª ed. Petrópolis: Vozes, 2002.

TAVARES, L. M. F. L.; SANTOS, L. M. M.; FREITAS, M. N. C. A educação inclusiva: um estudo sobre a formação docente. Revista Brasileira de Educação Especial, Marília, v. 22, n. 4, p. 527-542, 2016. Disponível em: https://www.scielo.br/pdf/rbee/v22n4/1413-6538-rbee22-04-0527.pdf. Acesso em: 03 jun. 2020.

VITALIANO, C. R. Análise da necessidade de preparação pedagógica de professores de curso de licenciatura para inclusão de alunos com necessidades especiais. Revista Brasileira de Educação Especial, Marília, v.13, n.3, p. 399-414, 2007. Disponível em: https://www.scielo.br/pdf/rbee/v13n3/a07v13n3.pdf. Acesso em: 03 jun. 2020. 
VITALIANO, C. R. (Org.). Formação de professores para inclusão de alunos com necessidades educacionais especiais. Londrina: EDUEL, 2010.

VIGOTSKI, L. S. Acerca dos processos compensatórios no desenvolvimento da criança mentalmente atrasada. Educação e Pesquisa, São Paulo, v. 44, 2018. Disponível em: https://www.scielo.br/pdf/ep/v44/1517-9702-ep-44-e44003001.pdf. Acesso em: 03 jun. 2020.

Itale LuCiane Cericato: Psicóloga, bacharela e licenciada pela Faculdade Paulistana de Ciências e Letras (2001). Mestre em Psicologia pela Universidade São Marcos (2006). Doutora em Educação: psicologia da educação pela Pontifícia Universidade Católica de São Paulo (2010). É docente do Programa de Pós-graduação stricto sensu em Educação da Universidade Federal de São Paulo.

Orcid: http://orcid.org/0000-0003-1163-3551

E-mail: itale.luciane@unifesp.br

Anderson RicARdo JúnIOR da Rocha SILVA: Licenciado em Ciências pela Universidade Federal de São Paulo (2021). Professor da Secretaria de Educação do Estado de São Paulo.

Orcid: https://orcid.org/0000-0002-5625-0880

E-mail: rj.krocha@smail.com

Este periódico utiliza a licença Creative Commons Attribution 3.0, para periódicos de acesso aberto (Open Archives Initiative - OAI). 